\title{
FRACTURES IN THEIR PRESENT SETTING
}

P. S. London, M.B.E., F.R.C.S.

The Birmingham Accident Hospital, Bath Row, Birmingham, I 5

\section{Fracture Services}

A GREAT step forward was taken when fractures came to be regarded as the responsibility of orthopædic surgeons, who set up fracture clinics and services throughout the country. Most fractures are closed and affect only one part of the body. The progress of the patient from arrival at hospital to final discharge is usually a leisurely one through the admission room, X-ray department, perhaps a ward and an operating theatre, the plaster room, then on to the fracture clinic, physiotherapy and occupational therapy, suitable work or retraining and finally back, if not to his customary place in society, at least to a useful one. Throughout this progress the need is for careful supervision rather than active or vigorous treatment.

The process of establishing this orderly and carefully managed train of events so greatly improved the quality of results after fractures that it can fairly be regarded as a revolution, albeit a largely bloodless one. There is now another

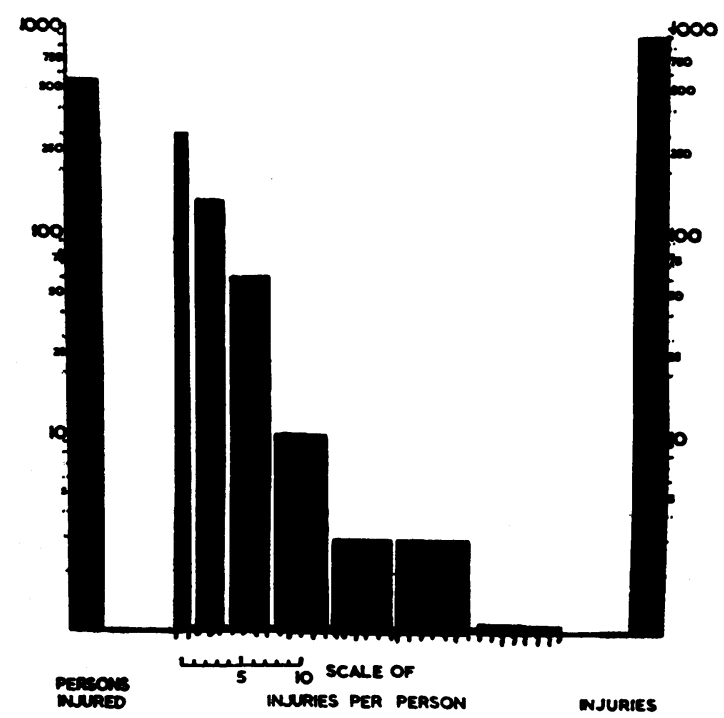

FIG. 1.-Total number and multiplicity of injuries of $55 \mathrm{I}$ persons admitted to an emergency unit (the vertical scale is logarithmic). Almost half the victims have two or more injuries each.

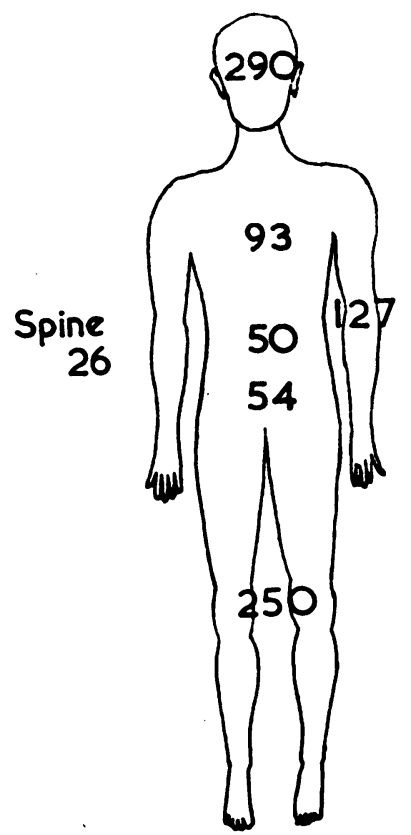

FIG. 2.-Number and distribution of 890 injuries in $55 \frac{\AA}{\mathbb{D}}$ persons.

revolution going on, but not by any means bloodless.

\section{Plating of Fractures}

Up to the time of Sir Arbuthnot Lane operation on fractures had been performed largely to rid the person of a limb in which sepsis was eithe regarded as inevitable or was already established ${ }_{\odot}$ Lane's technical skill enabled him to achieve b plating results that at the time seemed little short of miraculous. As with all brilliant innovators he acquired a following that may have equalled hinor in enthusiasm but fell far short in skill and judgment. Plating came to be condemned bu్ many and since that time there have been cycles of support for and condemnation of internal fixation. Important grounds for criticism were removed when the danger of corrosion wasp realized and the search for inert metals bore fruit. Internal fixation is more widely used now 
than ever before and disapproval, or outright condemnation, has not lagged behind this current fashion.

\section{Flexibility of Approach}

The spectator on the field of fractures may be forgiven if he forms the impression that there are opposed and even irreconcilable schools of closed and open (and usually fixative) methods of treatment. Dispassionate consideration will suggest that the methods are not mutually exclusive but complementary, and that achieving a uniformly high standard of results throughout the entire range of fractures of all kinds depends upon carefully selecting the appropriate method for the individual case.

\section{Fractures and Severe Injuries}

The blood shed in the present revolution comes

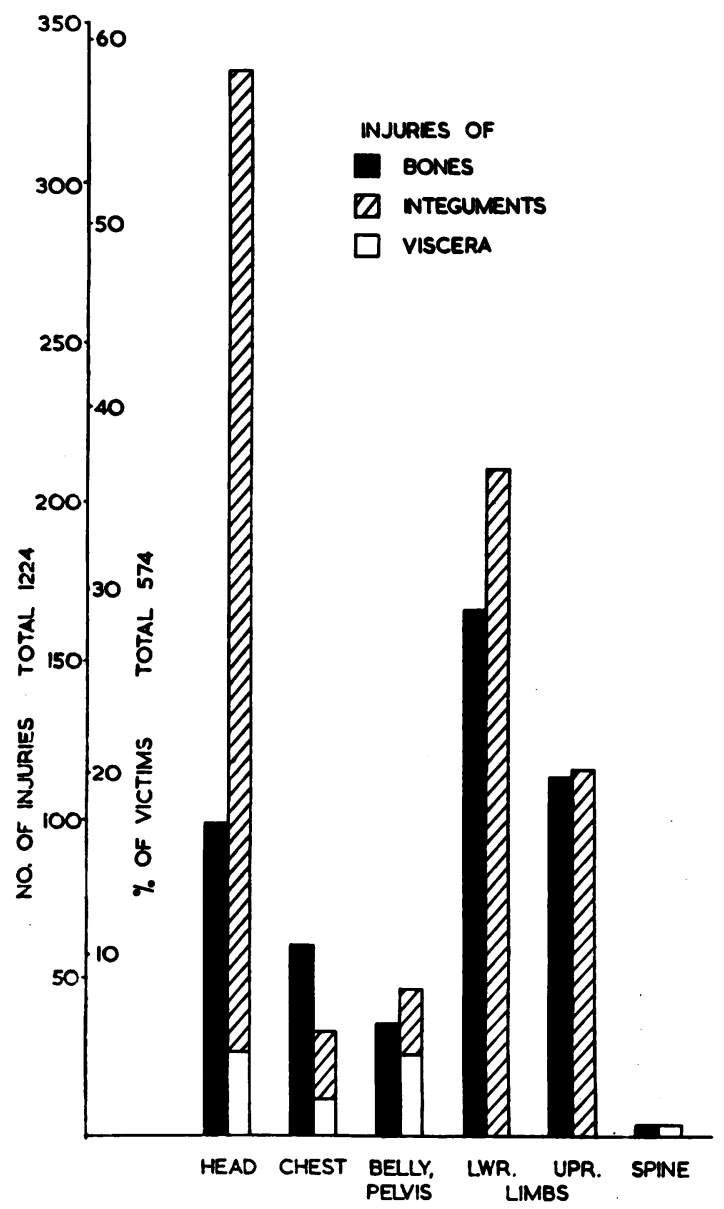

Frg. 3.-Distribution of 1,224 important injuries in 574 persons reaching hospital alive after road accidents (after Gissane, 1962).

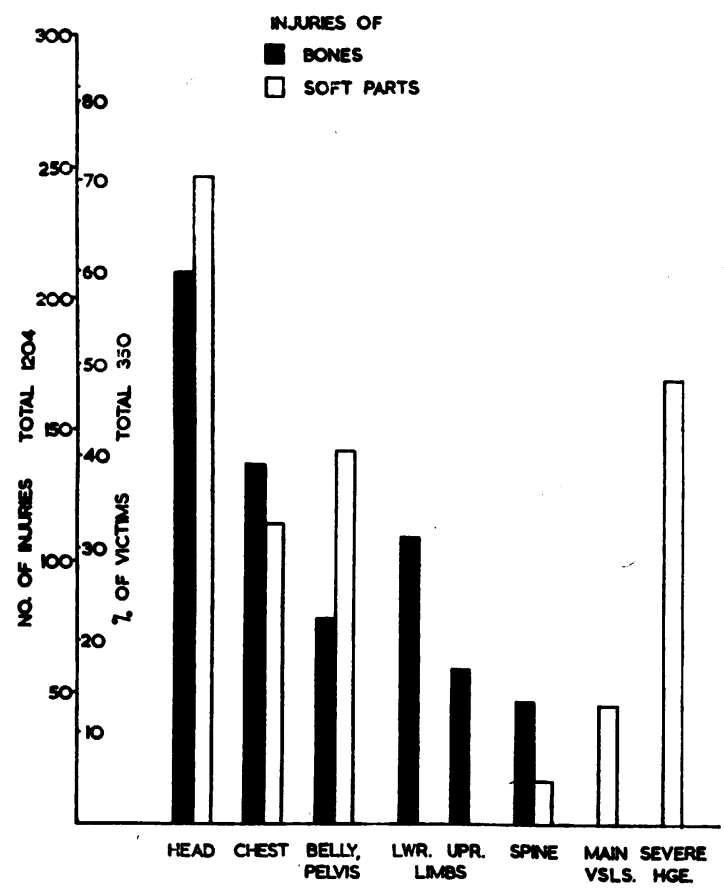

FIG. 4.-Distribution of 1,204 important injuries in those killed by road accidents (after Gissane and Bull, I96I).

not so much from operations on fractures as from the fractures themselves and from the injuries that go with them. The customary definition of a fracture refers only to bone but for all practical purposes there is no fracture so mild that it leaves the soft parts unharmed. Indeed the injured soft parts may be far more important than the broken bone: one need only consider the relative importance of a crack in the skull and an extradural hæmatoma or of broken ribs and rupture of the spleen or liver. Looked at in this light, fractures take their place among woundsbreaches in the continuity of tissue-but with the special feature of impairing stability and form.

Our present way of life depends upon movement of machines, vehicles and persons, often at high speed and not always predictably or under proper control. The result is that each year about one hundred thousand persons are seriously injured and eight thousand of them die in our industries and on our roads.

Figs. 1, 2, 3 and 4 present fractures in a current setting, a setting in which they provide roughly half the victims' injuries, a setting in which the individual patient may suffer as many as five or six important injuries. Persons admitted from all sources to the special emergency unit at the Birmingham Accident Hospital had an average 
FIG. 5.-A characteristic pattern of fractures resulting from car crashes.

of one-and-a-half important injuries each, the victims of road accidents reaching hospital alive an average of just over two (Fig. 3) and those killed by road accidents an average of three-anda-half important injuries each (Fig. 4). No part of the body is inviolable and accidental violence knows neither surgical nor anatomical boundaries.

The fractures are often severe and affect more than one limb or several parts of the same limb (Fig. 5). In the British Army nearly 50 years ago open fractures of the shaft of the femur carried a mortality rate of about $80 \%$. Our present knowledge of oligæmic shock and the importance of blood transfusion (Grant and Reeve, 195I ; Clarke, Fisher, Topley, Davies and Bull, 1956; Clarke, Fisher, Topley and Davies, 196r; Artz, Howard, Sako, Bronwell and Prentice, r955) has made it possible not merely to keep very severely injured persons alive but to operate on them according to their needs shortly after they have been injured (Fig. 6). It is this fact of saving life after severe injury that has made it necessary to treat fractures as well as other injuries of great severity. Surviva has created problems that were hardly known unt comparatively recent years. The problem is partly one of tissue-craft for the injuries themselves: and partly one of timing; the scale of days o weeks or even months that suits the vast majoritis of fractures has to be cut down to hours on sometimes minutes when injuries are numerous and severe. The problem is also a matter of balancing the requirements of one injury agains another. In some cases fractures have to takesecond place to other injuries, in others adequater resuscitation followed by a necessary life-saving operation may provide an opportunity for carryingu out definitive treatment of a fracture within a few hours of injury (Fig. 7).

\section{Principle and Practice}

A generally accepted practice in treating wounds is to hold the injured tissues together b $\bar{D}$ 


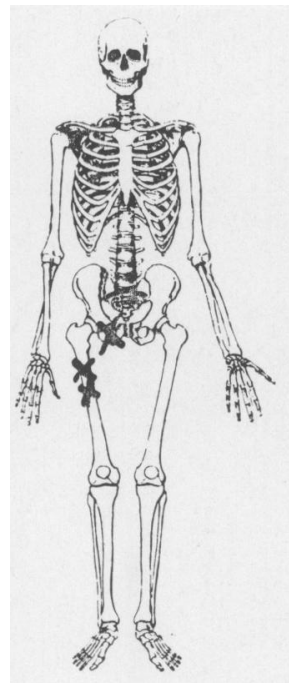

8 HOURS' DELAY

Not transtused

DIED ON ADMISSION

FIG. 6.-Multiple closed fractures and the importance of bleeding.

stitches of one sort or another until the healing process has restored something like normal tensile strength. The principle upon which this practice is based is equally applicable to the hard parts but most often is applied to them by way of external splintage. However, as has been shown (Hicks, 1960), there are circumstances in which external splintage can actually cause movement at the fracture site. Whatever the effect this has upon union of the fracture there can be little doubt about the possible and damaging effects of movement and displacement of bone upon the integrity and healing of suture-lines and on skin grafts nearby.

\section{Internal Fixation of Fractures}

If internal fixation is undertaken in emergency cases it can be justified only because its likely advantages are judged at least to balance its disadvantages. McLaughlin (1962) regards internal fixation as being absolutely necessary when it provides the only means of treating a fracture, perhaps to save a limb, or life itself. Relative necessity exists when a surgeon of mature judgment and wide experience considers that internal fixation offers the better prospect of success. Weighing the advantages and disadvantages of internal fixation may have to take into account injuries other than the fracture. Either can adversely affect the other. The restless patient with

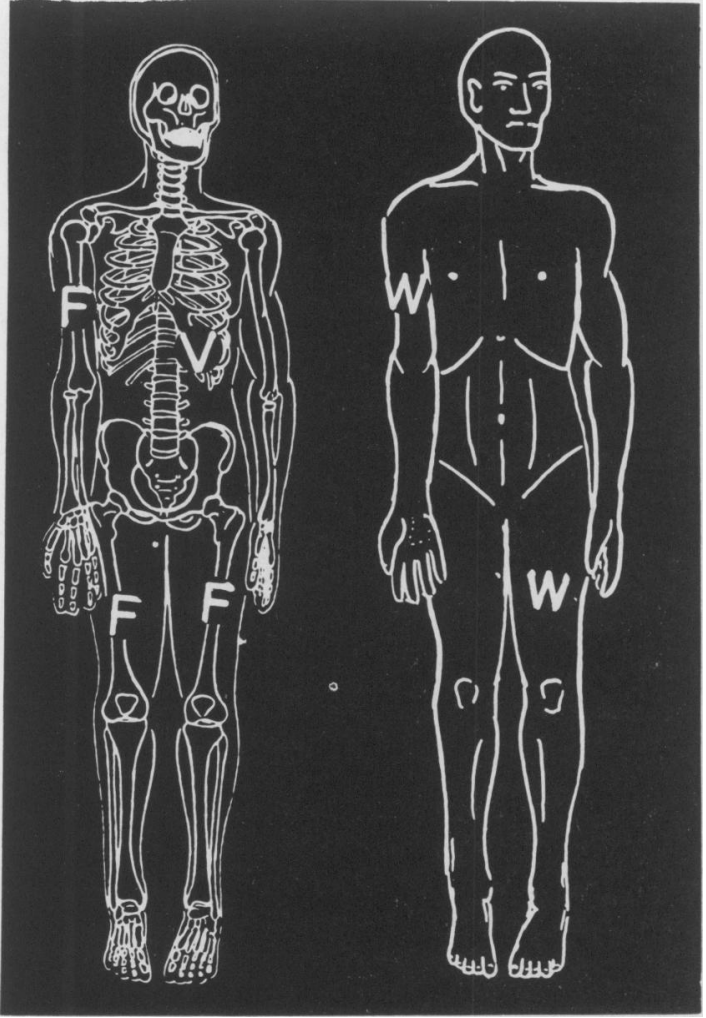

Fig. 7.-Multiple injuries. Immediate splenectomy (V) and Küntscher nailing of fracture of one femur. Other fractures splinted and wounds closed. Given 12 bottles of blood.

F : Fracture. W: Wound. V: Visceral injury.

a head injury can gravely complicate an originally simple fracture and if fit for operation at all may be more safely treated by internal fixation.

The victim of multiple injuries is sometimes more easily nursed if he can be freed from the encumbrance of external splints. The aged are liable to deteriorate rapidly if confined to bed but they can withstand multiple fractures and, if necessary, their fixation remarkably well provided that they are adequately protected against the hazards of oligæmia and cerebral hypoxia. It is a great advantage if they can be rendered comfortably active or even able to get up again within days of their injuries. In these aspects of the present setting of fractures, operating on them can save both life and limb.

The dangers of operating on fractures include aggravating shock, causing skin to die, promoting infection and delaying union. Formidable as these dangers are they are neither inevitable nor insuperable.

Shock after serious injury is largely due to bleeding and it can be abolished and sometimes 


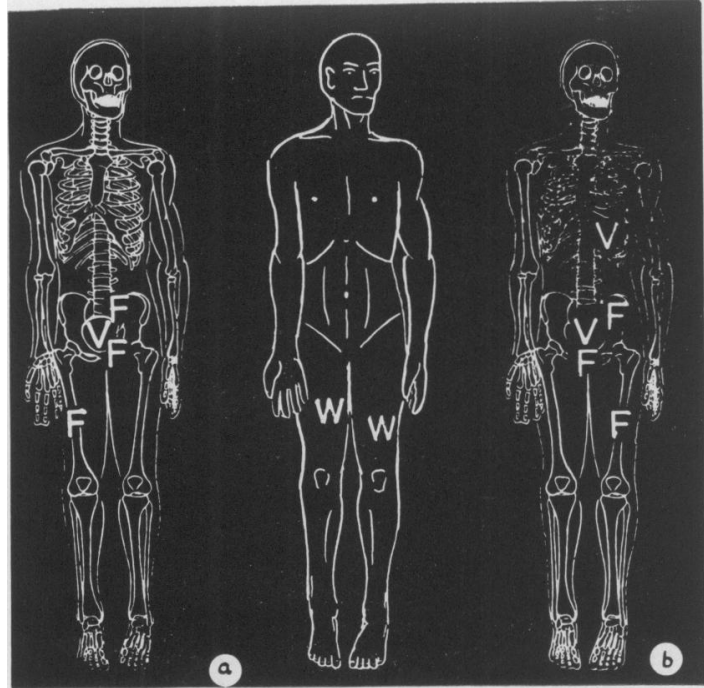

FIG. 8.- Two of seven survivors from a single crashed car. All b's injuries were closed.

$\mathrm{V}$ : Ruptures of bladder and diaphragm.

Each received ten bottles of blood during resuscitation and primary treatment. Both recovered with negligible disability.

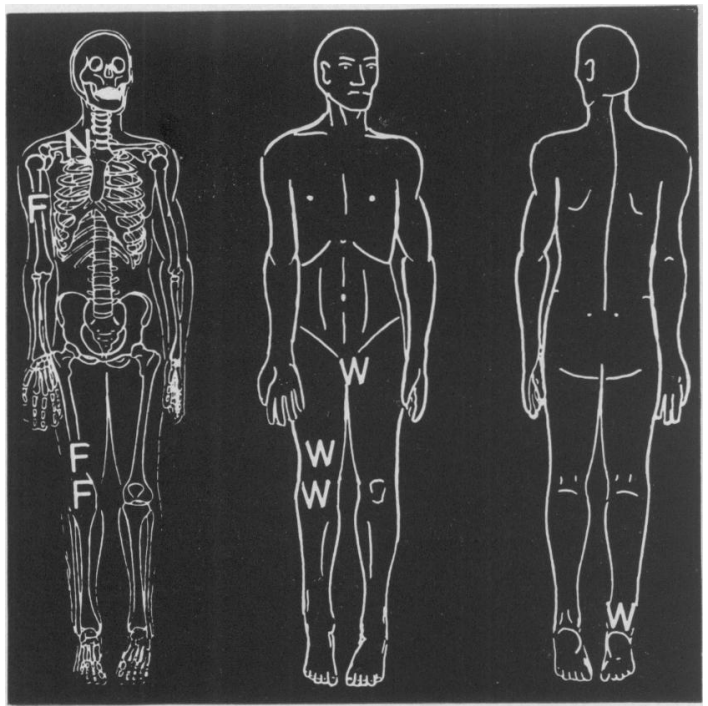

Fig. 9.-Male, aged 22. All injuries except torn brachial plexus (N) operated on and given 22 bottles of blood within a few hours; 36 hours later red cell volume found by measurement to be $35 \%$ below the expected figure.

(a) Injury chart.

entirely prevented by promptly replenishing the circulation and keeping pace with further loss. Large amounts of blood may be required (Figs. 6, $8,9)$.
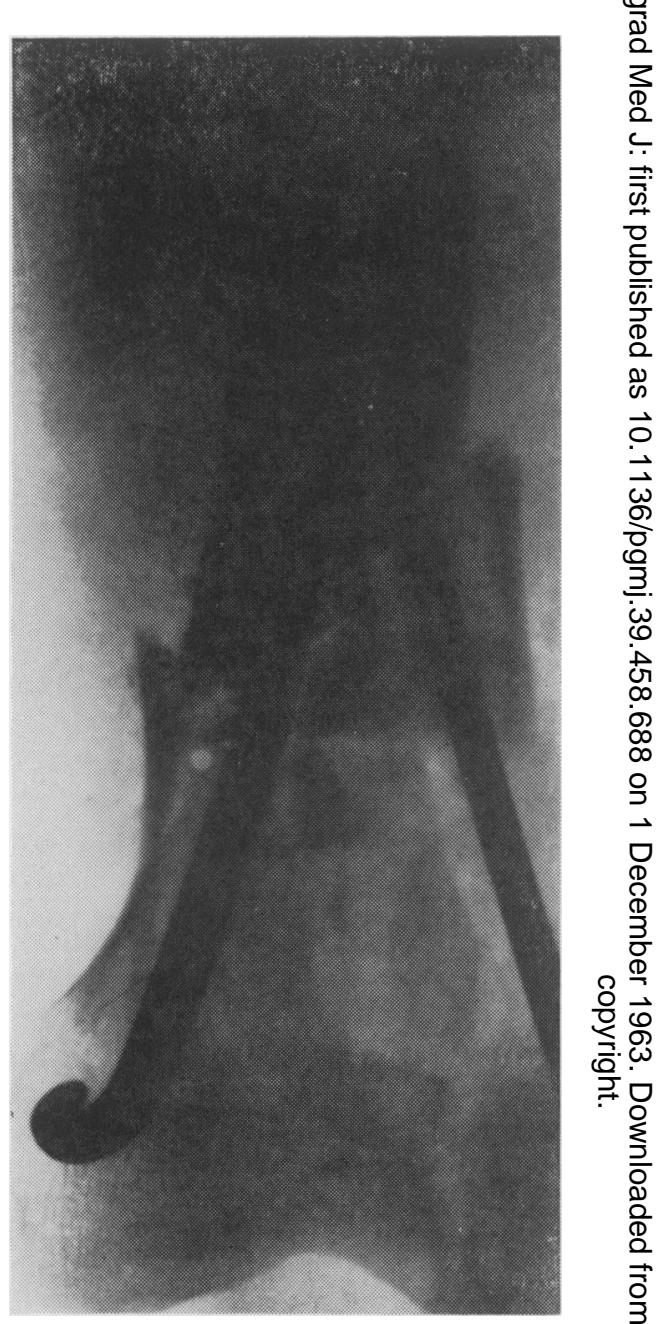

Fig. 9. (b).- - Right thigh at two weeks; the patella was removed.

Death of skin is a serious danger, especially with fractures of the tibia. It may be bruised abraded or stripped from its moorings anळ్ tensely distended by blood (Fig. Io). Whether ok not there is already a wound a surgical incisiors increases the risk that skin will die and allow infection.

Infection is possible after any operation and the् surgeon must accept responsibility for sepsis after operation on a closed fracture. In the cas of open fractures, internal fixation is more ofterw followed by sepsis than is simple closure of the wound (Hicks, 1957) but this is to some extent reflection of the great severity of those fractures for which internal fixation is used in the hope of saving a useful limb (Fig. 9). Hicks (1963) has found that the amputation rate for all fractures of 


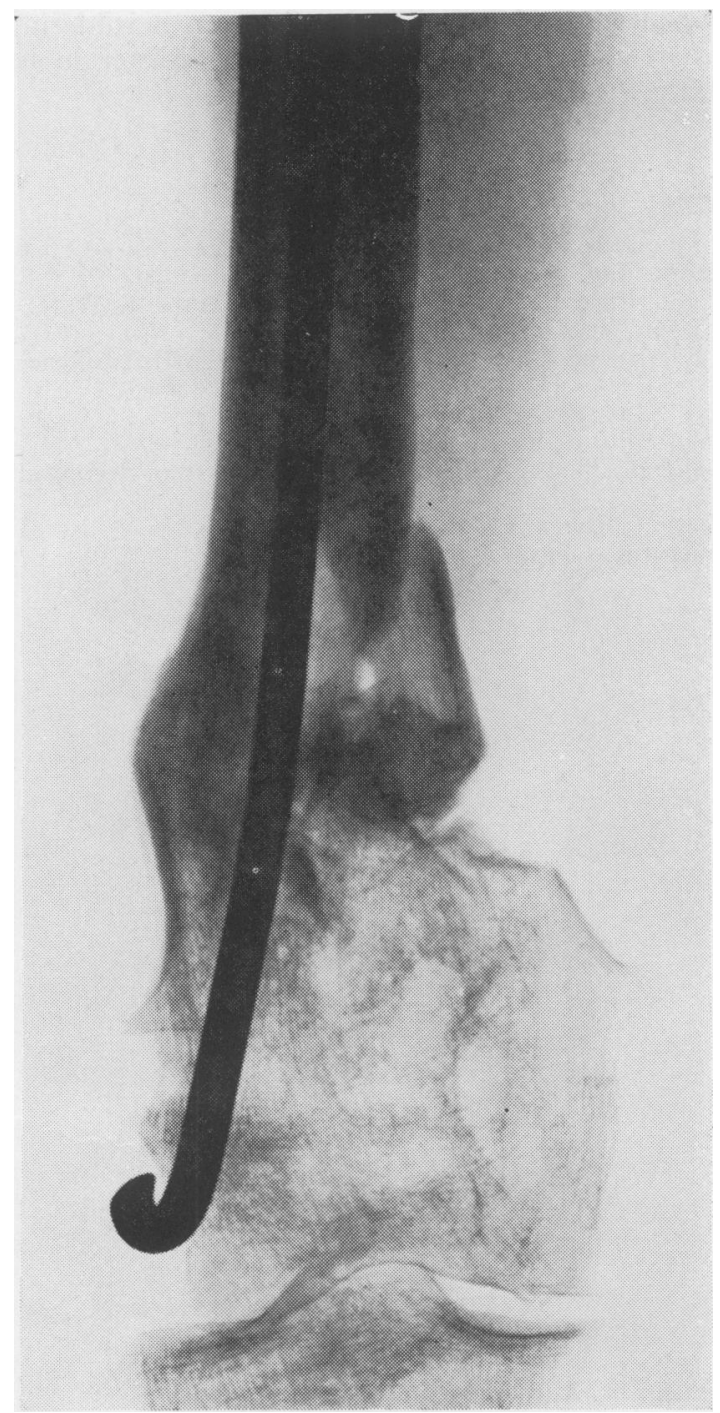

FIG. $9(c)$.-Right femur at five months. Increasing weight borne during last two months.

the shafts of adults' tibiæ fell from $1.8 \%$ to $0.8 \%$ after the introduction of rigid fixation.

Delayed union is not so much the fault of the metal as the consequence of accidental or surgical stripping and devitalization of bone and like the foregoing hazards it is to some extent under the control of the surgeon.

\section{Choice of Method}

Success in treating any fracture, whether solitary or accompanied by other injuries, does not depend upon the use of any one method but upon the ability to choose wisely from the now

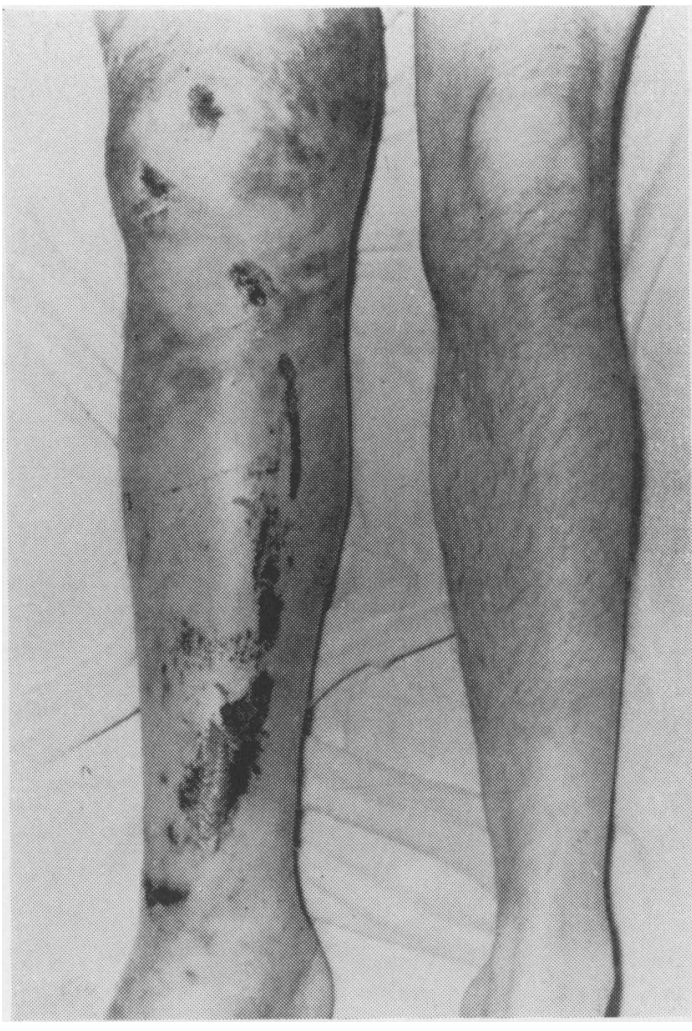

Fig. 10.-A limb ballooned by subcutaneous bleeding

considerable range of techniques and appliances. Were it possible for all fractures to be brought successfully to union it would entail the use now of plaster, now of traction, now of plates, now of nails-and there are several patterns of each, with their several advantages and shortcomingsnow of screws or pins, encircling wires or prostheses. As well as experienced familiarity with the techniques applicable to broken bones the present setting of fractures requires of those that treat them at least a working knowledge of resuscitation from shock and respiratory injury as well as of the effects and sometimes the competing therapeutic needs of injuries of the head, abdomen, skin, nerves and blood vessels.

\section{Accident Services}

All that has been said and written in recent years about accident services is directed towards ensuring that as far as is possible all the appropriate skills and facilities shall be promptly available to those that need them. Whether the injuries be fractures or otherwise, when they are severe or numerous they demand care of high quality and more purposefully organized services 
than those that at present so often leave the victims to the care of inadequately trained or inappropriately experienced doctors for whom casualty duty is an unwelcome or bewilderinga chore that can bring tragedy and disaster in its train.

\section{REFERENCES}

Artz, C. P., Howard, J. M., Sako, Y., Bronwell, A. W., and Prentice, T. (r 955): Clinical Experiences in the Early Management of the Most Severely Injured Battle Casualties, Ann. Surg., 141, 285.

Bull, J. P.: Clarke, R., and Fisher, M. R.; Topley, E., and Fisher, M. R.; Clarke, R.; Davies, J. W. L.; $\mathbb{\mathbb { D }}$ Flear, C. T. G. (1 956): Brit. F. clin. Pract., Io. Pp. 743; 746; 770; 777; 785; 787.

—-, Fisher, M. R., Topley, E., and Davies, J. W. L. (1961): Extent and Time of Blood-Loss after Civilian Injuries Lancet, ii, $38 \mathrm{I}$.

Gissane, W. (1962): The Basic Surgery of Major Road Injuries, Ann. roy. Coll. Surg. Engl., 30, 28 r.

$\overrightarrow{\text { Grant, R. T., and Reeve, E. B. (I95I): 'Observations on the General Effects of Injury in Man', Spec. Rep. Ser. Med } \vec{\omega}}$ Res. Coun. (Lond.), No. 277.

Hicks, J. H. (1957): The Relationship Between Metal and Infection, Proc. roy. Soc. Med., 50, 842. (1960): External Splintage as a Cause of Movement at Fractures, Lancet, i, 667. ( 1963 ): Personal communication.

Mclaughlin, H. L. (1962): Personal communication. 